\title{
Hypoglycemic Actions of Disopyramide Enantiomers as Bitartrate Salts
}

\author{
Setsuya TAKEUCHI* and Tadao OKAMURA*
}

(Received on May 14, 1987)

* Department of Pharmacology, Nippon Medical School, 1-1-5 Sendagi, Bunkyo-ku, Tokyo 113, Japan

The effects of enantiomeric bitartrates of disopyramide on blood glucose levels and heart rate were evaluated in Donryu rats. A transient blood glucose lowering response was noted 2 to $3 \mathrm{hr}$ after oral administration of $300 \mathrm{mg} / \mathrm{kg}$ d-disopyramide. After oral administration of 1-disopyramide, however, a significant hypoglycemic response was noted which lasted for more than $5 \mathrm{hr}$. This hypoglycemic action of the individual enantiomers was significantly more potent in the levorotatory form than in the dextrorotatory form, with a relative potency of $\operatorname{Pr}(d / 1)=11$. 8. The inhibitory effect of the individual enantiomers on the heart rate calculated in vivo from ECG tracings and in vitro from the contraction rate of a right atrial preparation showed no significant difference between the two stereoisomers. These results suggest the possibility of a decrease in the incidence of clinical hypoglycemia while maintaining an acceptable cardiac action by utilizing the dextrorotatory stereoisomer of disopyramide alone.

Key words : uisopyramide, enantiomers, relative potency, hypoglycemia, adverse effect

Hypoglycemic symptoms have been reported as a side effect of the clinical use of racemic disopyramide, a widely known as antiarrhythmic agent. ${ }^{1-9)}$ Pharmacological studies have been conducted to elucidate the mechanism of the development of these hypoglycemic symptoms after

*日本医科大学薬理学教室 画113 東京都文京区千駄木1-1-5 application of racemic disopyramide. Two mechanisms of action of this drug have already been reported. ${ }^{10)}$ However, the danger of hypoglycemia during administration of racemic disopyramide continues to be still a clinical problem. This report concerns the possibility of alleviation or prevention of hypoglycemia related to racemic disopyramide administration. A key may be the evaluation of the relationship between the 
appearance of hypoglycemia with the use of racemic disopyramide and the stereochemical characteristics of the twin disopyramide enantiomers.

\section{Materials and Methods}

All experiments were carried out using male Donryu rats of 250 to $300 \mathrm{~g}$ body weight.

\section{Blood glucose level studies}

In rats standardized by the modified SatoTakeuchi's method, ${ }^{11}{ }^{12)} 30$ to $300 \mathrm{mg} / \mathrm{kg}$ of the tested drugs were administered orally. Blood samples were obtained before and 1 to $5 \mathrm{hr}$ after administration. The blood glucose determinations were made with the glucose-oxidase method (Blood Sugar GOD. Perid. Test, Boehringer Mannheim).

\section{Chronotropic action studies}

The first experiment was under in vitro conditions. The heart was removed from a rat under ether anesthesia and the atria dissected from the ventricle were separated into left and right atrium. ${ }^{13,14)}$ The right atrial preparation was set in a Magnus' tube containing $10 \mathrm{ml}$ of Tyrode's solution maintained at $37^{\circ} \mathrm{C}$ and equilibrated for 30 min under an atmosphere of $95 \% \mathrm{O}_{2}$ and $5 \%$ $\mathrm{CO}_{2}$. The preparation was loaded with $0.5 \mathrm{~g}$ of resting tension to record the generated isotonic contractions by means of a transducer (Nippon Kohden, TD 112 S). The automatic rhythm frequency of the preparation was calculated from the changes in the recorded contractions. The action of the test drugs on the preparation was observed for $15 \mathrm{~min}$, after the addition of the drugs to the Magnus' tube. A second experiment was performed in vivo. The baseline cardiac rate was calculated based on an ECG recording. This ECG was recorded with a polygraph from a rat anesthetized with pentobarbital sodium ( $40 \mathrm{mg}$ / $\mathrm{kg} \mathrm{ip).} \mathrm{The} \mathrm{test} \mathrm{drugs} \mathrm{were} \mathrm{administered} \mathrm{in-}$ travenously through a polyethylene tube inserted into the jugular vein.

\section{Drugs and statistics}

The drugs used in the present experiment were enantiomeric bitartrates of disopyramide (Diso), d-disopyramide bitartrate (d-Diso) and 1-disopyramide bitartrate (1-Diso) (Yoshitomi Pharmaceutical Industries, Ltd.). They were dissolved in physiological saline prior to use. The data are expressed as the mean $\pm S$. D. Statistical analysis were performed using Student's t-test and parallel line assay.

\section{Results}

\section{Blood glucose changes}

After oral administration of 30 to $300 \mathrm{mg} / \mathrm{kg} \mathrm{l}$ Diso or d-Diso, the blood glucose level decreased (Tabs. 1,2). The maximum fall of the mean blood glucose was noted 2 to $3 \mathrm{hr}$ after administration of $300 \mathrm{mg} / \mathrm{kg}$ d-Diso. The rate of decrease was about $30 \%$. The blood glucose level returned to the normal level during the fifth hour (Tab. 1). A more significant decrease of blood glucose level was noted from 2 to $5 \mathrm{hr}$ after the administration of $300 \mathrm{mg} / \mathrm{kg}$ of 1-Diso. The maximum decrease in mean blood glucose was noted during the fifth hour after the administration of 1-Diso, with a rate of decrease of about $45 \%$ (Tab. 2). The relationship between the dose and the fall in blood glucose in the second and fifth hour after administration of the enantiomers is shown Fig. 1 (A, B). Over the range of 30 to $300 \mathrm{mg} / \mathrm{kg}$ of the Diso enantiomers, linear regression and parallelism were noted in each case $(P<0.05)$. Relative potency ( $\mathrm{Pr}$ ) of the hypoglycemic action calculated from the dose response curve obtained the second hour after administration of the Diso enantiomers was $\operatorname{Pr}(\mathrm{d}$-Diso/1-Diso) $=11.2$ (Fig. 1A). The value during the fifth hour after administration was $\operatorname{Pr}(\mathrm{d}$-Diso/l-Diso $)=11.8$ (Fig. 1B) . 
Tab. 1 Blood Glucose Levels after Oral Administration of d-Disopyramide in Rats

\begin{tabular}{|c|c|c|c|c|c|c|c|}
\hline \multirow{3}{*}{ Dose $(\mathrm{mg} / \mathrm{kg})$} & & \multirow{3}{*}{$\begin{array}{c}\text { No. of } \\
\text { trials }\end{array}$} & \multicolumn{5}{|c|}{ Blood glucose level $(\mathrm{mg} / \mathrm{dl})$} \\
\hline & & & \multicolumn{5}{|c|}{ Time after administration ( $\mathrm{hr})$} \\
\hline & & & 1 & 2 & 3 & 4 & 5 \\
\hline Saline & & 2 & $\begin{array}{l}109 \pm 1.0 \\
(110,108)\end{array}$ & $\begin{array}{c}117 \pm 7.5 \\
(124,109)\end{array}$ & $\begin{array}{c}109 \pm 8.0 \\
(101,117)\end{array}$ & $\begin{array}{l}117 \pm 1.5 \\
(118,115)\end{array}$ & $\begin{array}{c}107 \pm 9.5 \\
(116,97)\end{array}$ \\
\hline d-Disopyramide & $30^{\prime}$ & 2 & $\begin{array}{l}113 \pm 5.5 \\
(102,113)\end{array}$ & $\begin{array}{l}96 \pm 1.0^{* *} \\
(95,97)\end{array}$ & $\begin{array}{l}96 \pm 1.0 \\
(97,95)\end{array}$ & $\begin{array}{l}107 \pm 0.5 \\
(106,107)\end{array}$ & $\begin{array}{c}106 \pm 11.5 \\
(117,94)\end{array}$ \\
\hline d-Disopyramide & 100 & 2 & $\begin{array}{l}107 \pm 3.0 \\
(104,110)\end{array}$ & $\begin{array}{c}93 \pm 7.5^{*} \\
(100,85)\end{array}$ & $\begin{array}{l}85 \pm 8.0^{*} \\
(77,93)\end{array}$ & $\begin{array}{l}90 \pm 1.5^{* *} \\
(88,91)\end{array}$ & $\begin{array}{c}98 \pm 9.0 \\
(107,89)\end{array}$ \\
\hline d-Disopyramide & 300 & 2 & $\begin{array}{l}112 \pm 11.5 \\
(123,100)\end{array}$ & $\begin{array}{l}85 \pm 14^{*} \\
(99,71)\end{array}$ & $\begin{array}{l}68 \pm 6.0^{* *} \\
(74,62)\end{array}$ & $\begin{array}{l}84 \pm 5.0^{* *} \\
(79,89)\end{array}$ & $\begin{array}{l}85 \pm 16 \\
(101,69)\end{array}$ \\
\hline
\end{tabular}

Five rats were used in one trial. Each value represents the mean $\pm \mathrm{SD}$. Values in parentheses were obtained in two trials. ${ }^{*} \mathrm{P}<0.05$ and ${ }^{* *} \mathrm{P}<0.01$ compared with each saline-treated control.

Tab. 2 Blood Glucose Levels after Oral Administration of 1-Disopyramide in Rats

\begin{tabular}{|c|c|c|c|c|c|c|c|}
\hline \multirow{3}{*}{ Dose $(\mathrm{mg} / \mathrm{kg})$} & & \multirow{3}{*}{$\begin{array}{l}\text { No. of } \\
\text { trials }\end{array}$} & \multicolumn{5}{|c|}{ Blood glucose level $(\mathrm{mg} / \mathrm{dl})$} \\
\hline & & & \multicolumn{5}{|c|}{ Time after administration $(\mathrm{hr})$} \\
\hline & & & 1 & 2 & 3 & 4 & 5 \\
\hline Saline & & 2 & $\begin{array}{l}94 \pm 8.0 \\
(102,86)\end{array}$ & $\begin{array}{l}95 \pm 11.5 \\
(106,83)\end{array}$ & $\begin{array}{c}101 \pm 3.0 \\
(104,98)\end{array}$ & $\begin{array}{l}99 \pm 2.5 \\
(96,101)\end{array}$ & $\begin{array}{l}109 \pm 7.0 \\
(116,102)\end{array}$ \\
\hline d-Disopyramide & 30 & 2 & $\begin{array}{l}113 \pm 12.5 \\
(125,100)\end{array}$ & $\begin{array}{l}84 \pm 20.5 \\
(104,63)\end{array}$ & $\begin{array}{l}90 \pm 18.0 \\
(108,72)\end{array}$ & $\begin{array}{l}93 \pm 22.5 \\
(115,70)\end{array}$ & $\begin{array}{l}85 \pm 17.0 \\
(102,68)\end{array}$ \\
\hline d-Disopyramide & 100 & 2 & $\begin{array}{c}101 \pm 8.5 \\
(92,109)\end{array}$ & $\begin{array}{c}79 \pm 7.0 \\
(72,86)\end{array}$ & $\begin{array}{l}76 \pm 3.0^{* *} \\
(73,79)\end{array}$ & $\begin{array}{l}74 \pm 6.5^{* *} \\
(67,80)\end{array}$ & $\begin{array}{l}68 \pm 3 \cdot 0^{* *} \\
(65,71)\end{array}$ \\
\hline d-Disopyramide & 300 & 2 & $\begin{array}{c}106 \pm 11.5 \\
(94,117)\end{array}$ & $\begin{array}{c}66 \pm 5.5^{*} \\
(71,60)\end{array}$ & $\begin{array}{l}70 \pm 8.0^{* *} \\
(62,78)\end{array}$ & $\begin{array}{c}57 \pm 21.0 \\
(36,78)\end{array}$ & $\begin{array}{l}56 \pm 13 \cdot 0^{* *} \\
(43,69)\end{array}$ \\
\hline
\end{tabular}

Five rats were used in one trial. Each value represents the mean \pm SD. Values in parentheses were obtained in two trials. ${ }^{*} \mathrm{P}<0.05$ and ${ }^{* *} \mathrm{P}<0.01$ compared with each saline-treated control.

The hypoglycemic effect of 1-Diso in the second and fifth hour after administration was significantly more potent than that of d-Diso $(\mathrm{P}<0.05)$.

\section{Chronotropic action in vitro and in vivo studies}

The contraction rate of a spontaneously beating right atrial preparation started to decrease following application of 100 to $150 \mu \mathrm{g} / \mathrm{ml}$ of Diso enantiomers, and disappeared about 7 to $8 \mathrm{~min}$ later. Figure 2 shows the decrease of the contraction rate 4 to 5 min after administration of Diso enantiomers. Such response showed a concentration-dependency curve. Calculation of the relative potency between the two Diso enantiomers revealed $\operatorname{Pr}(\mathrm{d}$-Diso/1-Diso $)=1.32$, with no significant difference in the inhibitory action on cardiac chronotropy between the two stereoisomers of the drugs.

The heart rate calculated from the ECG tracing decreased in response to the administration of Diso enantiomers. The negative effect on heart rate showed a dose-dependency curve over the dosage range of 3 to $30 \mathrm{mg} / \mathrm{kg}$. Figure 3 illustrates the decrease in heart rate 30 to $60 \mathrm{sec}$ after administration of Diso enantiomers. The relative potency between the two stereoisomers was calculated as $\operatorname{Pr}(\mathrm{d}$-Diso/1-Diso $)=0.69$, with no significant difference in the inhibitory action on 
Fig. 1 Dose response curves for decrease of blood glucose levels obtained from the

estimates $2 \mathrm{hr}$ (A) or $5 \mathrm{hr}$ (B) after oral administration of disopyramide enantiom

ers in rats. For details, see Tabs. 1 and 2. •: d-Diso, $\bullet$ : 1-Diso.

Fig. 2 Dose response curves for decrease of

beating rate obtained from the esti

mates 4-5 min after application of

disopyramide enantiomers in isolated

rat atria.

Each point represents the mean $\bullet$

SD of 5 trials. $\bullet:$ d-Diso, $\bullet$ : 1-Diso.

cardiac chronotropy between the enantiomers.

Discussion

Racemic disopyramide can be separated into

levorotatory and dextrorotatory compounds, fo
1Fig. 3 Dose response curves for decrease of

heart rate obtained from the estimates

30-60 sec after administration of dis

opyramide enantiomers in rats.

Each point represents the mean $\cdot$

SD of 5 trials. $\bullet:$ d-Diso, $\bullet$ : 1-Diso.

lowed by crystallization of each stereoisomer.15)

The examination of a potential relationship be

tween the stereochemical characteristics of each

enantiomer of disopyramide and hypoglycemic

action is of special interest. Separation of the 
hypoglycemic tendency from cardiac effects implies the possibility of alleviation or prevention of this adverse reaction to disopyramide racemate.

Kimura et al. $^{10)}$ classified the hypoglycemic responses to racemic Diso into two main types: initial and sustained hypoglycemia. The results obtained in the present study support this classification. Blood glucose level decreased by about $35 \%$ within $2 \mathrm{hr}$ after 1-Diso administration, followed by a persistence of the hypoglycemia, and maintenance of a low blood glucose level of about $45 \%$ of normal levels even 5 hr later. No tendency toward spontaneous recovery of blood glucose was noted. This hypoglycemic action of 1-Diso, however, was about 11 to 12 times as strong as that of d-Diso. A significant difference in the intensity of the hypoglycemic action was noted between the two stereoisomers of Diso. This intense and sustained hypoglycemia in response to 1-Diso closely resembles the sustained type of hypoglycemia induced by the racemate. The transient milder hypoglycemia in response to d-Diso closely resembles the initial type of hypoglycemia. Consequently, the sustained hypoglycemic action of racemic Diso is thus most probably due to the levorotatory form.

Burke et al., ${ }^{15)}$ on the other hand, studied the antiarrhythmic properties of enantiomeric bitartrate salts of disopyramide, and concluded that there was no significant difference in antiarrhythmic properties between the levorotatory and dextrorotatory forms. In the present study, the results obtained support their conclusion.

By separating the enantiomeric disopyramides with these pharmacological actions and using them in clinical therapy, it may be possible to change the degree and frequency of the adverse reactions found in the racemate. Clinical use of the dextrorotatory form alone, as an antiarrhyth- mic agent, after separating the stereoisomers would probably decrease the incidence of clinical hypoglycemia markedly.

According to the report of Cook et al., ${ }^{16)}$ the first-pass metabolism of enantiomeric disopyramides was greater in d-Diso, and the stereoselective metabolism of Diso varies according to the animal species tested. In the experiment of the authors, this first-pass metabolism may possibly represent a background for the milder hypoglycemic action of d-Diso compared to 1-Diso. After the administration of a clinical dose of racemic disopyramide to rats, no hypoglycemic response was seen in rats yet. The appearance of clinical hypoglycemia as a side effect of the clinical administration of a therapeutic dose may be related to some factors of patients themselves, such as a stereoselective metabolism.

However, further studies are necessary to confirm the safety of enantiomers.

We are indebted to Yoshitomi Pharmaceutical Industries, Ltd. for a generous gift of disopyramide enantiomers, 1-disopyramide and d-disopyramide.

\section{References}

1) Goldberg, I. J., Brown, L. K. and Rayfield, E. J. : Disopyramide (Norpace)-induced hypoglycemia. Am. J. Med., 69 : 463-466 (1980).

2) Taketa, K. and Yamamoto, Y.: Hypoglycemic effect of disopyramide in a case of diabetes mellitus under insulin treatment. Acta Med. Okayama, $34: 289-292$ (1980).

3) Quevedo, S. F., Krauss, D. S., Chazan, J. A. et al. : Fasting hypoglycemia secondary to disopyramide therapy. Report of two cases. JAMA, $245: 2424$ (1981).

4) Koizumi, J., Kawasaki, S., Ueno, H. et al. : A diabetic woman showing a hypoglycemic effect induced by disopyramide (Rythmodan). J. Jpn. Diab. Soc., $24: 861-866$ (1981). (in Japanese)

5) Hartingan, J. D. : Severe hypoglycemia com- 
plicating disopyramide (Norpace) therapy. A case report. Neb. Med. J., 68:36-38(1983).

6) Strathman, I., Schubert, E. N., Cohen, A. et al. : Hypoglycemia in patients receiving disopyrar mide phosphate. Drug Intell. Clin. Pharm., $17: 635-638$ (1983).

7) Stapleton, J. T. and Gillman, M. W. : Hypoglycemic coma due to disopyramide toxicity. South Med. J., 76:1453 (1983).

8) Semel, J. D., Wortham, E. and Karl, D. M. : Fasting hypoglycemia associated with disopyramide. Am. Heart J., 106 : 1160-1161 (1983).

9) Turtzo, D. F. and Ghatak, P. K. : Disopyramide induced hypoglycemia. Penn. Med., 89 : 34-36 (1986).

10) Kimura, F., Mitamura, H., Fukazawa, S. et al. : Studies on the mechanism of disopyramideinduced hypoglycemia. Jpn. J. Clin. Pharmacol. Ther., $17: 379-389$ (1986).

11) Takeuchi, S. : Anti-diabetic drugs. Ban, Y., Kitagawa, H., Miyaki, T. et al. (Eds.) : Method in Drug Research, Asakura Shoten, Tokyo, pp. 351-361 (1968). (in Japanese)
12) Takeuchi, S., Fukano, T., Dohi, C. et al. : Hypoglycemic effect of 3-aza bicyclo 3, 3, 1 nonanes in rats and rabbits. Jpn. J. Pharmacol., $21: 811-817$ (1971).

13) Levy, J. L. : Isolated atrial preparation. Schwartz, A. (Ed.) : Methods in Pharmacology, Appleton-Century-Crofts, New York, pp. 77-104 (1971).

14) Grupp, I. L. and Grupp, G. : Isolated heart preparations perfused or superfused with balanced salt solution. Schwartz, A. (Ed.) : Method in Pharmacology, Plenum Press, New York, pp. 111-128 (1984).

15) Burke, T. R., Jr., Nelson, W. L., Mangion, M. et al. : Resolution, absolute configuration, and antiarrhythmic properties of the enantiomers of disopyramide, 4-(diisopropylamino)-2-(2pyridyl)-2-phenylbutyramide. J. Med. Chem., $23: 1044-1048$ (1980).

16) Cook, C. S., Karim, A. and Sollman, P. : Stereoselectivity in the metabolism of disopyramide enantiomers in rat and dog. Drug Metab. Dispos., 10:116-121 (1982). 